\section{Inconsistencies in cardiovascular data from COX-2 inhibitor trials-is it a class effect?}

The recent editorials in the New England Journal of Medicine about inaccuracies in cardiovascular data in the publication of the VIGOR (Vioxx Gastrointestinal Outcomes Research) study $^{1,2}$ has prompted us to report similar inaccuracies in the CLASS study (Celecoxib Long-term Arthritis Safety Study), which were identified during a systematic review of the cardiovascular effects of celecoxib. ${ }^{3}$

Like the VIGOR study, CLASS was designed primarily to compare the incidence of upper gastrointestinal adverse events resulting from a COX-2 specific inhibitor with those of conventional non-steroidal anti-inflammatory drugs (NSAIDs) in patients with arthritis. As with the VIGOR study, in CLASS there were also inconsistencies in the serious adverse cardiovascular events reported in the different published reports.

The outcomes of CLASS have been reported in two peer-reviewed journals ${ }^{4,5}$ and in a number of documents posted on the Food and Drug Association website, of which the medical officer review is the most complete. ${ }^{6}$ We have reviewed the data from these three major publications. ${ }^{4-6}$ In September 2000 the initial 6-month data were published by Silverstein and colleagues in JAMA in which no cardiovascular deaths were reported (Table 1). ${ }^{4}$ Also in September 2000, the FDA medical officer review of celecoxib data supplied by GD Searle \& Co, reported that

Table 1 Mortality data reported in the three CLASS (Celecoxib Longterm Arthritis Safety Study) publications

\begin{tabular}{|c|c|c|c|c|}
\hline & \multicolumn{2}{|c|}{ Cardiac death } & \multirow{2}{*}{$\begin{array}{l}\text { Relative } \\
\text { risk }\end{array}$} & \multirow[b]{2}{*}{$95 \% \mathrm{Cl}$} \\
\hline & Celecoxib & NSAID & & \\
\hline $\begin{array}{l}\text { Silverstein } 2000 \\
\text { (6 months data) } \\
\text { (Ref. 4) }\end{array}$ & $\begin{array}{l}\text { Not } \\
\text { reported }\end{array}$ & $\begin{array}{l}\text { Not } \\
\text { reported }\end{array}$ & - & - \\
\hline $\begin{array}{c}\text { White } 2002 \\
(\text { Ref. 5)* }\end{array}$ & $10 / 3987$ & $10 / 3981$ & 1.0 & $0.42-2.40$ \\
\hline FDA 2000 (Ref. 6) $)^{\dagger}$ & $5 / 3987$ & 8/3981 & 0.62 & $0.20-1.91$ \\
\hline
\end{tabular}

*Data taken from Table 2, page 428

'Data taken from Table 38, page 54

NSSAID, non-steroidal anti-inflammatory drugs; Cl, confidence interval; FDA, Food and Drug Administration
Table 2 Myocardial infarction data reported in the three CLASS (Celecoxib Long-term Arthritis Safety Study) publications

\begin{tabular}{|c|c|c|c|c|}
\hline & \multicolumn{2}{|c|}{ Myocardial infarction } & \multirow{2}{*}{$\begin{array}{l}\text { Relative } \\
\text { risk }\end{array}$} & \multirow[b]{2}{*}{$95 \% \mathrm{Cl}$} \\
\hline & Celecoxib & NSAID & & \\
\hline $\begin{array}{l}\text { Silverstein } 2000 \\
\text { (6 months data) } \\
(\text { Ref. } 4)^{\star}\end{array}$ & $10 / 3987$ & $11 / 3981$ & 0.91 & $0.39-2.13$ \\
\hline $\begin{array}{l}\text { White } 2002 \\
\quad(\text { Ref. 5) }\end{array}$ & 26/3987 & $15 / 3981$ & 1.73 & $0.92-3.26$ \\
\hline $\begin{array}{r}\text { FDA } 2000 \\
\text { (Ref. 6) }\end{array}$ & 19/3987 & $13 / 3981$ & 1.46 & $0.72-2.95$ \\
\hline
\end{tabular}

*Data taken from Table 4, page 1252

'Data taken from Table 2, page 428

Data taken from Table 41, page 57

See Table 1 for key to abbreviations

in CLASS there were five and eight cardiovascular deaths in the celecoxib and NSAID groups, respectively, during the full 12-month study period or within the following 28 days (Table 1). ${ }^{6}$ In the subsequent 2002 American Journal of Cardiology publication of the cardiovascular events from CLASS, a total of 10 cardiovascular deaths were reported in each of the celecoxib and NSAID groups (Table 1). ${ }^{5}$ It is difficult to understand why all the cardiovascular deaths would have occurred after 6 months of treatment, and how there could be such major discrepancies between the two complete study reports for such a definite outcome measure as death.

Similarly, there were inconsistencies between the three sources of CLASS data in the reporting of myocardial infarction (Table 2). For example, in the publications of the entire CLASS data, one reported 26 myocardial infarctions in the celecoxib group and 15 in the NSAID group ${ }^{5}$, whereas the other reported 19 and 13 myocardial infarctions, respectively. ${ }^{6}$

These findings add to the concerns previously expressed regarding the selective and partial reporting of the gastrointestinal side effects from the CLASS study and that the published CLASS study differs from the original protocol in primary outcomes, statistical analysis, trial duration and conclusions. ${ }^{7-10.7,8}$

Thus history appears to have repeated itself in two respects. First, in CLASS there were inconsistencies in the reporting of cardiovascular data. Of greater concern is the identification that in the two major safety studies of the most commonly used COX-2 specific inhibitors there were major inconsistencies in reporting of the cardiovascular events. Thus, there would seem to be a systemic problem in research conduct in this field. There 
are considerable public health, pharmaceutical, regulatory and clinical implications.

\section{Competing interests None.}

\section{Mark Weatherall ${ }^{1}$ Sarah Aldington ${ }^{2}$ Brent Caldwell ${ }^{2} \quad$ Richard Beasley ${ }^{2}$ \\ ${ }^{1}$ Wellington School of Medicine \& Health Sciences, Wellington; \\ ${ }^{2}$ Medical Research Institute of New Zealand, Wellington, New Zealand \\ Correspondence to: Professor Richard Beasley \\ E-mail: Richard.Beasley@mrinz.ac.nz}

\section{REFERENCES}

1 Curfman GD, Morrissey S, Drazen JM. Expression of concern: Bombardier et al "Comparison of upper gastrointestinal toxicity of rofecoxib and naproxen in patients with rheumatoid arthritis". $N$ Engl $\mathrm{J}$ Med 2000;343:1520-8; 2005;353:2813

2 Curfman GD, Morrissey S, Drazen JM. Expression of concern reaffirmed. [http://content.nejm.org/cgi/content/abstract/NEJMe068054]

3 Caldwell B, Aldington S, Weatherall M, Shirtcliffe P, Beasley R. Risk of cardiovascular events and celecoxib: a systematic review and metaanalysis. J R Soc Med 2006;99:132-40
4 Silverstein FE, Faich G, Goldestein JL, et al. Gastrointestinal toxicity with celecoxib vs nonsteroidal anti-inflammatory drugs for osteoarthritis and rheumatoid arthritis. The CLASS study: a randomized controlled trial. JAMA 2000;284:1247-55

5 White WB, Faich G, Whelton A, et al. Comparison of thromboembolic events in patients treated with celecoxib, a cyclooxygenase-2 specific inhibitor, versus ibuprofen or diclofenac. Am J Cardiol 2002;89:425-30

6 Witter J. Celebrex capsules (celecoxib). NDA 20-998/S-009. Medical Officer Review. US Department of Health and Human Services Food and Drug Administration, 2000 [http://www.fda.gov/ohrms/dockets/ac/01/ briefing/3677b1_03_med.pdf]

7 Jüni P, Rutjes AWS, Dieppe PA. Are selective COX 2 inhibitors superior to traditional non steroidal anti-inflammatory drugs? BMJ 2002; 324:1287-8

8 Wright JM, Perry TL, Bassett KL, Chambers GK. Reporting of 6month vs 12 -month data in a clinical trial of celecoxib [Letter]. JAMA 2001;286:2398-9

9 Berg Hrachovec J, Mora M. Reporting of 6-month vs 12-month data in a clinical trial of celecoxib [Letter]. JAMA 2001;286:2398

10 Celecoxib and the CLASS trial: data massaging by industry. Prescribe Int 2002;11:190-1 